\title{
Produção de compostos fenólicos a partir de células imobilizadas do líquen Parmotrema andinum (Müll. Arg.) Hale e avaliação de atividade antimicrobiana'
}

\author{
Nadejda de Azevedo Nóbrega ${ }^{2}$, Sheyla Mara Ribeiro² ${ }^{2}$ Eugênia Cristina Pereira ${ }^{3}$, Marcelo Marcelli ${ }^{4}$, Mônica Cristina \\ Barroso Martins ${ }^{5}$, Emerson Peter da Silva Falcão ${ }^{6,9}$, Norma Buarque de Gusmão e Nicácio Henrique da Silva ${ }^{8}$
}

Recebido em 23/07/2010. Aceito em 11/01/2012

\begin{abstract}
RESUMO
(Produção de compostos fenólicos a partir de células imobilizadas do líquen Parmotrema andinum (Müll. Arg.) Hale e avaliação de atividade antimicrobiana). A utilização de metabólitos secundários obtidos de líquens, na indústria farmacêutica, de cosmético, têxtil e de alimentos deve ser criteriosa, visto que a extração e isolamento desses metabólitos requerem uma grande quantidade de biomassa dificilmente renovável, devido ao crescimento lento do líquen. Atualmente, é possível obter substâncias liquênicas tanto por cultivo de tecidos, como por imobilizações celulares e enzimáticas, a partir do talo in natura, utilizando pequena quantidade de material liquênico. Portanto, este trabalho objetiva investigar a produção de compostos fenólicos a partir de células imobilizadas de Parmotrema andinum (Müll. Arg.) Hale utilizando acetato de sódio como precursor da biossíntese dos fenóis. Ensaios de atividade antimicrobiana com extratos orgânicos do talo in natura, eluatos celulares e do ácido lecanórico isolado de P. andinum Hale demonstraram ação contra bactérias Gram-positivas. Através de testes biocromatográficos foi possível associar a atividade antibacteriana ao ácido lecanórico e uma substância não identificada presente na espécie. As substâncias produzidas através de imobilização celular não exibiram ação inibitória frente os microrganismos testados.
\end{abstract}

Palavras-chave: ácido lecanórico, atividade antibacteriana, imobilização celular

\begin{abstract}
(Production of phenolic compounds from immobilized cells of the lichen Pamotrema andinum (Müll. Arg.) Hale and evaluation of antimicrobial activity). Secondary metabolites obtained from lichens should be carefully used by the pharmaceutical, cosmetic, textile and food industries because the extraction and isolation of these metabolites requires large amounts of biomass, which is not renewable due to how slow lichens grow. Nowadays, it is possible to obtain these substances either by tissue culture or cell and enzymatic immobilizations, from an in natura thallus, using a small amount of lichenous material. Therefore, this work aimed to investigate the production of phenolic compounds from Parmotrema andinum (Müll. Arg.) Hale immobilized cells, using sodium acetate as a precursor in the biosynthesis of phenols. Testing of antimicrobial activity with organic extracts of the in natura thallus, cell eluate and lecanoric acid isolated from P. andinum Hale showed antimicrobial activity against Gram-positive bacteria. Through biochromatographic assays, it was possible to associate the antibacterial activity to the lecanoric acid and to another unidentified substance. The substances produced by cell immobilization did not exhibit any inhibitory action against tested microorganisms.
\end{abstract}

Key words: lecanoric acid, antibacterial activity, cell immobilization

\footnotetext{
Parte da dissertação de Mestrado do primeiro Autor

2 Universidade Federal do Pará, Departamento de Ciências da Saúde, Belém, PA, Brasil

3 Universidade Federal de Pernambuco, Departamento de Ciências Geográficas, Recife, PE, Brasil

4 Instituto de Botânica de São Paulo, São Paulo, SP, Brasil

5 Universidade Federal de Pernambuco, Programa de Pós-Graduação em Bioquímica e Fisiologia, Recife, PE, Brasil

6 Universidade Federal de Pernambuco, Centro Acadêmico de Vitória de Santo Antão, Vitória de Santo Antão, PE, Brasil

7 Universidade Federal de Pernambuco, Departamento de Antibióticos, Recife, PE, Brasil

8 Universidade Federal de Pernambuco, Departamento Bioquímica, Recife, PE, Brasil

9 Autor para correspondência: emerson_falco@yahoo.com.br
} 


\section{Introdução}

São encontradas no Nordeste do Brasil várias espécies de líquens, cujos metabólitos possuem comprovada ação farmacológica. Diversos compostos secundários de origem liquênica são conhecidos por apresentarem atividades biológicas variadas. Ao estudar espécies encontradas em solos arenosos de tabuleiros costeiros (vegetação de cerrado) do Estado da Paraíba (Nordeste do Brasil), Pereira et al. (1997) detectaram ação antimicrobiana em extratos orgânicos de Cladonia substellata e C. crispatula, identificando o ácido úsnico como princípio ativo das espécies. Seus estudos demostraram que tal substância impedia o desenvolvimento de fungos e bactérias Gram-positivas.

Além da aplicação farmacológica, as substâncias liquênicas também são amplamente empregadas nas indústrias têxteis e de alimentos. Diante desta diversidade de usos, seu emprego comercial deve ser criterioso, devido ao fato da necessidade de destruição de grande quantidade de biomassa dificilmente renovável (Nash III, 2008). Portanto, uma alternativa à produção de substâncias liquênicas com fins industriais e científicos, sem grandes impactos à micota liquenizada, é o uso de técnicas de imobilização celular.

A imobilização celular e enzimática é um recurso biotecnológico que consiste em posicionar fisicamente células em uma região ou espaço definido com aproveitamento da sua atividade catalítica, ou parte dela, para uso continuado e repetido. Pode ser aplicada quando o processo bioquímico em foco requer a participação de complexos multienzimáticos de enzimas intracelulares lábeis de difícil obtenção na forma pura, e geralmente não disponíveis comercialmente. É uma alternativa interessante para o uso de sistemas enzimáticos purificados (Shibata et al. 1987).

A própria célula organiza e fornece as condições ótimas para o seu funcionamento: $\mathrm{pH}$ ideal e osmolaridade, cofatores e coenzimas, resultando numa maior estabilidade. Apresenta à vantagem de reutilização em ciclos sucessivos, comum aos demais biocatalisadores imobilizados, a economia de tempo e recursos que seriam dispendiosos na extração e purificação das enzimas (Yamamoto et al. 1976).

As células imobilizadas oferecem uma grande flexibilidade de uso, podendo ser usadas desvitalizadas e em diversos estados metabólicos e fisiológicos, permeabilizadas em repouso, em crescimento, ou podem ter enzimas ou rotas enzimáticas bloqueadas visando impedir a decomposição do produto desejado, ou manipuladas, limitando o organismo de algum nutriente essencial, favorecendo as reações desejáveis (Svitel et al. 1998).

Desta forma, em virtude das propriedades descritas para as substâncias liquênicas, os objetivos deste trabalho foram avaliar a capacidade de produção de metabólitos celulares pelas células de $P$. andinum, comparando-os com aqueles produzidos no talo in natura verificando a atividade antibacteriana dos mesmos.

\section{Materiais e métodos}

\section{Material liquênico}

Parmotrema andinum (Müll. Arg.) Hale, foi coletado no município de Saloá, localizado a uma latitude $08^{\circ} 5833$ sul e longitude $36^{\circ} 4115$ oeste, a uma altitude de 745 metros no Estado de Pernambuco, Nordeste do Brasil. As amostras do líquen foram identificadas através de análise dos caracteres morfológicos e químicos do talo por um dos autores (M. P. Marcelli), sendo mantidas em caixas de papel até o momento da realização dos experimentos.

\section{Preparo dos extratos orgânicos, isolamento e purificação do ácido lecanórico e da atranorina do talo in natura}

$\mathrm{O}$ material liquênico $(5 \mathrm{~g})$ foi seco à temperatura ambiente $\left(28 \pm 3^{\circ} \mathrm{C}\right)$ e os extratos orgânicos foram obtidos utilizando-se os solventes: éter, clorofórmio e acetona (20 $\mathrm{mL}$ de cada), sendo posteriormente filtrados e rotaevaporados a $40^{\circ} \mathrm{C}$ até a secura.

O ácido lecanórico foi isolado do extrato etéreo com bicarbonato de sódio a $5 \%$ e precipitado com ácido cloridrico na mesma concentração, sendo purificado através de recristalizações sucessivas com benzeno/etanol (1:1). O residuo do extrato etéreo foi dissolvido com clorofórmio e precipitado sucessivamente com metanol resfriado até obtenção da atranorina purificada, de acordo com Asahina \& Shibata (1954).

Ensaios de imobilização celular e obtenção dos eluatos celulares

As suspensões celulares foram obtidas através de suave maceração do material liquênico $(2 \mathrm{~g})$ em almofariz com água destilada, seguida por filtração. As células em suspensão foram imobilizadas em $90 \mathrm{~g}$ de caulinita previamente hidratada por duas horas. A mescla células/caulinita foi empacotada em 3 colunas de vidro $(30 \times 7 \mathrm{~cm})$ e a cada uma foi adicionada $50 \mathrm{~mL}$ de acetato de sódio nas concentrações de 0,$01 ; 0,1 ; 1,0,10,0$ e 20,0 mM, pH 8,5. Os biorreatores foram mantidos sob luz branca $\left(125 \mu \mathrm{mol} \mathrm{m} \mathrm{m}^{-2} \mathrm{~s}^{-1}\right)$ durante todo o experimento. Aliquotas diárias de $25 \mathrm{~mL}$ de cada biorreator foram coletadas na primeira semana e aliquotas semanais a partir da segunda semana, durante trinta dias. O mesmo volume do acetato de sódio foi sempre reposto após cada coleta.

Para extração dos fenóis foram utilizados $25 \mathrm{~mL}$ do sistema éter/acetato de etila $(65: 35 \mathrm{v} / \mathrm{v})$ com agitação, seguido por uma segunda extração com o mesmo volume de solução de clorofórmio/acetonitrila (60:40 v/v). A Absorvância dos dois extratos orgânicos foi obtida em espectrofotômetro $(254$ e $366 \mathrm{~nm})$. Em seguida, os extratos foram reunidos em um mesmo recipiente conforme a concentração do acetato de sódio; depois se evaporou a mistura de solventes até secura sob fluxo de $\mathrm{N}_{2}$ para posterior análise (Pereira et al., 1995). 
Análise dos extratos liquênicos por cromatografias em camada delgada (CCD) e líquida de alta eficiencia (CLAE)

Para análise qualitativa (CCD) os extratos orgânicos do talo in natura e os eluatos celulares foram diluídos à concentração de $2,0 \mathrm{mg} \mathrm{mL}^{-1}$, e aplicados $15 \mu \mathrm{L}$ em cromatoplacas de sílica gel F $254+366$ Merck $(20$ x $20 \mathrm{~cm}$ de espessura), cuja fase móvel consistiu do sistema de solventes tolueno:dioxano:ácido acético (180:45:5 v/v/v). As bandas foram observadas sob luz UV em dois comprimentos de onda ( 254 e $366 \mathrm{~nm}$ ), posteriormente reveladas com ácido sulfúrico a $10 \%$ e aquecidas a $100{ }^{\circ} \mathrm{C}$ por 10 minutos. As bandas foram identificadas através da comparação dos valores de $\mathrm{Rf}$ com aqueles obtidos com os respectivos padrões (Culberson, 1972).

$\mathrm{Na}$ análise qualitativa em CLAE, os extratos orgânicos do talo in natura e os eluatos celulares foram solubilizados em metanol espectroscópico, à concentração de $1,0 \mathrm{mg} \mathrm{mL}^{-1}$, e os padrões do ácido lecanórico e atranorina a $0,1 \mathrm{mg} \mathrm{mL}^{-1}$ dissolvidos nos respectivos solventes de extração, sendo analisados em cromatógrafo líquido Hitachi, acoplado a um detector de UV (CG-435-B) a $254 \mathrm{~nm}$, e injetados em coluna de fase reversa MicroPack MHC-18 (300 mm x 4mm I.D.); volume de injeção de $20 \mu \mathrm{L}$ tendo como fase móvel metanol/água/ácido acético (80:19:0,5 v/v/v) em sistema isocrático; pressão $88 \mathrm{~atm}$; temperatura ambiente de $(28 \pm$ $\left.3{ }^{\circ} \mathrm{C}\right)$. As substâncias foram identificadas através da comparação dos tempos de retenção (Tr) com aqueles obtidos com os padrões (Legaz \& Vicente, 1983).

A determinação dos teores de ácido lecanórico e da atranorina nos extratos orgânicos foi realizada através da curva de calibração por cromatografia líquida de alta eficiência, utilizando-se diferentes soluções do citado ácido nas concentrações crescentes (Fig. 1A e B).

\section{Atividade antimicrobiana}

Para os ensaios antimicrobianos, cepas de Staphylococcus aureus (DAUFPE-01), Bacillus subtilis (DAUFPE-16), o Micrococcus lutteus (DAUFPE-06), bactérias Gram-positivas e Escherichia coli (DAUFPE-224), Pseudomonas aeruginosa (DAUFPE-39), bactérias Gram-negativas e, duas leveduras Candida albicans (DAUFPE-2007) e uma cepa da mesma espécie isolada de caso clínico, no Departamento de Micologia da Universidade Federal de Pernambuco, foram selecionadas.

Os ensaios foram realizados através de teste de difusão em meio sólido. Placas de Petri (140 mm) contendo $25 \mathrm{~mL}$ de meio Agar Muller-Hinton foram inoculadas com 100 $\mu \mathrm{L}$ da suspensão dos microrganismos teste $10^{7} \mathrm{UFC} \mathrm{mL}^{-1}$. Discos de papel $(6,0 \mathrm{~mm})$ foram impregnados com $50 \mu \mathrm{L}$ das soluções de cada extrato (etéreo, clofórmico e acetônico) e substâncias puras (ácido lecanórico e atranorina), nas concentrações respectivas de $1,0 \mathrm{mg} \mathrm{mL}^{-1}$ e $2,0 \mathrm{mg} \mathrm{mL}^{-1}$ e, em seguida, depositados sobre o meio previamente inoculado. As placas foram incubadas a $37^{\circ} \mathrm{C}$, para bactérias e $30^{\circ} \mathrm{C}$ para a levedura por $24 \mathrm{~h}$. Foram utilizados éter, clorofórmio e acetona como referência negativa nos discos controle, além de ácido úsnico $(50 \mu \mathrm{L})$, na concentração de $1,0 \mathrm{mg} \mathrm{mL}^{-1} \mathrm{e}$ $2,0 \mathrm{mg} \mathrm{mL}^{-1}$ e o padrão comercial da levofloxacino a $0,5 \mu \mathrm{g}$ $\mathrm{mL}^{-1}$, como referência positiva. A atividade antimicrobiana foi determinada através da mensuração, expressa em milímetros, dos halos de inibição do crescimento microbiano ao redor dos discos (Bauer et al., 1966).

\section{Biocromatografia}

Foi selecionado para o ensaio biocromatográfico o extrato que apresentou maior atividade nos testes antibacterianos em cultura, isto é, o extrato clorofórmico, e o microrganismo mais sensível, ou seja, B. subtilis. O extrato foi aplicado em placas de sílica gel $F_{254+366}$ Merck, na concentração de $3,0 \mathrm{mg} \mathrm{mL}^{-1}$. A cromatografia foi desenvolvida no sistema tolueno:dioxano:ácido acético $(180: 45: 5 \mathrm{v} / \mathrm{v})$, sendo utilizados como padrões a atranorina, os ácidos lecanórico e úsnico. A cromatoplaca foi armazenada por $24 \mathrm{~h}$, em condições assépticas, até a completa evaporação do eluente. Em seguida, foi depositada em placa de Petri vazia $(180 \mathrm{~mm})$, recebendo uma camada de meio Agar Müller-Hinton (25 $\mathrm{mL}$ ), previamente inoculado com $100 \mu \mathrm{L}$ de suspensão de B. subtilis na concentração de $10^{7} \mathrm{UFC} \mathrm{mL} \mathrm{L}^{-1}$. As substâncias que exibiram atividade antimicrobiana foram reconhecidas através das zonas de inibição formadas ao redor das bandas separadas por cromatografia (Falcão et al., 2002).

\section{Resultados e discussão}

Durante todo o experimento de imobilização celular foi observada a produção de compostos por $P$. andinum, o que indica a manutenção da vitalidade celular no decorrer dos ensaios. Porém a concentração do precursor biossintético (acetato de sódio) não influenciou na produtividade das células imobilizadas (Fig. 2), uma vez que o comportamento foi semelhante para todas as concentrações. Estes dados corroboram com os relatos de Pereira et al. (1999), que ao analisarem amostras de imobilzados de células de Cladonia corallifera, observaram não haver diferenças na produção dos fenóis mesmo variando a concentração do precursor. Entretanto, Pereira et al. (2002), observaram comportamento diferente em amostras de eluatos obtidos das Cladonias verticillaris e salzmannii, cuja produção dos fenóis é crescente e proporcional a concentração do precursor.

Alguns fatores podem influenciar na produção de compostos fenólicos por células imobilizadas. A exemplo, Pereira et al. (2002) observaram que o estado de fertilidade do líquen parece alterar a produção dos metabólitos secundários, uma vez que em células de Cladia aggregata o maior pico de produção se deu nos períodos de infertilidade do talo.

Nas amostras analisadas por CCD a presença do ácido lecanórico nos extratos acetônico e etéreo do talo natural foram evidentes. Já no extrato clorofórmico foi observada a presença de atranorina, além de um composto não 

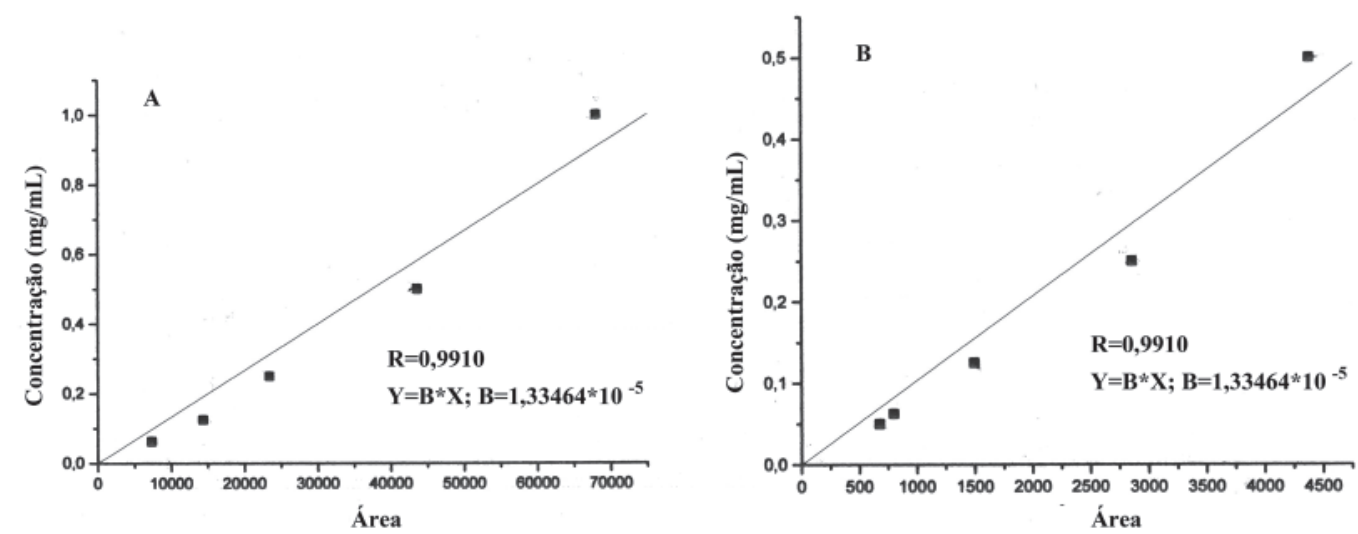

Figura 1. Curva de calibração dos padrões de atranorina (A) e ácido lecanórico (B) em CLAE.

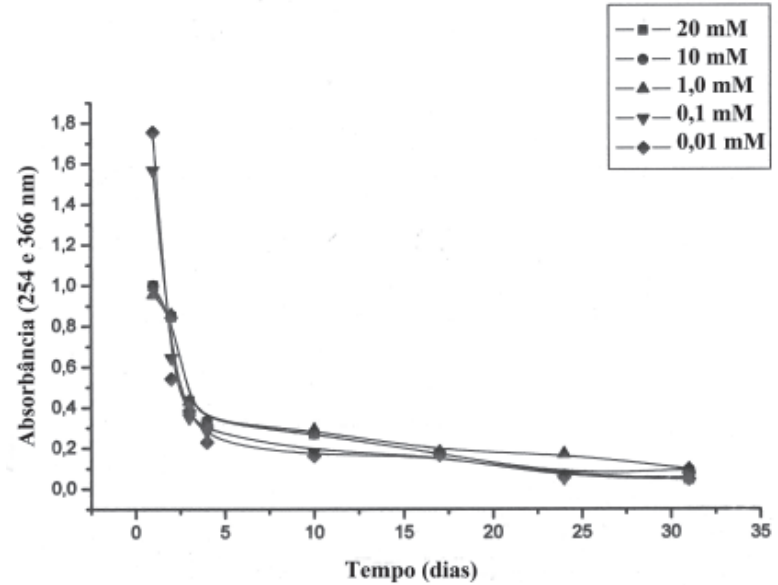

Figura 2. Produção de metabólitos secundários por células de Parmotrema andinum imobilizadas em caulinita, sob diferentes concentrações de acetato de sódio.

identificado. Nos eluatos identificou-se uma substância cujo Rf é próximo ao do ácido lecanórico (Fig. 3). Outras espécies congêneres também apresentam o referido metabólito secundário, como a Parmotrema stuppeum (Jayaprakasha \& Rao 2000). A presença de um composto a mais no extrato clorofórmico não é fato surpreendente, visto que a região geográfica em adição à influência microclimática interfere sobremaneira no teor e natureza de substâncias produzidas por liquens (Pereira et al. 2002). A presença do ácido lecanórico em espécies submetidas a uma incidência luminosa relativamente alta, tal qual a $P$. andinum, também foi verificada por Millot et al. (2007) que encontrou altas concentrações da referida substância em Ochrolechia parella.

A análise em CLAE, utilizando os extratos orgânicos do talo in natura (Fig. 4, 5 e 6), dos cinco eluatos celulares (Fig. 7) e das substâncias purificadas de P. andinum, ácido lecanórico e atranorina (Fig. 8A e B) confirmou os resultados obtidos nos testes em CCD. Foi constatada a presença da atranorina ( $\operatorname{Tr} 27,77$ min., Fig. 8 B) nos extratos etéreo e clorofórmico (Fig. 4 e 5), cujos teores, calculados segundo as curvas de calibração foram de 9,6\% e 1,61\% (Fig. 1A e B). Já o ácido lecanórico (Tr 5,95 min., Fig. 8 A) foi detectado nos extratos etéreo $(35,56 \%)$ e acetônico, sendo este último aquele que apresentou uma maior concentração do referido composto fenólico $(65,64 \%)$.

A presença de outras substâncias liquênicas, além das referidas na literatura foi verificada em todos os extratos orgânicos, o que sugere estudos posteriores da química de $P$. Andinum. Este fato é observado principalmente nos extratos etéreo e acetônico (Fig. 4 e 6). Nestes verificaram-se, através de CLAE, a presença de compostos não identificados com $\operatorname{Tr}=21,67 \mathrm{~min}$. (extrato etéreo) e $\operatorname{Tr}=13,47$ min. (extrato acetônico), sendo este último possivelmente o co-responsável pela atividade antibacteriana observada, uma vez que também está presente nos extratos, etéreo e clorofórmico (Fig. 4 e 5).

A análise em CLAE dos eluatos celulares confirma que não houve biossíntese das duas substâncias referidas na literatura para a espécie. Por outro lado, foi registrada a produção de compostos não identificados com Tr bastante próximos (Fig. 7). Possivemente tais substâncias sejam intermediárias metabólicas dos compostos principais referidos para $P$. Andinum. Outros autores observaram a produção de atranorina ao invés do composto majoritário (ácido fumarprotocetrárico) em Cladonia verticillaris e $C$. clathrata. A não produção dos principais compostos de um líquen por meio de células imobilizadas é atribuída à separação da alga e fungo, durante o processo de extração celular, dependendo da forma de contato entre os simbiontes (Pereira et al. 1999). Em outros casos, como foi observado em Cladonia salzmannii, células imobilizadas produziram os mesmos compostos do talo in natura, os ácidos barbático e taminólico (Pereira et al. 2002).

A síntese de outras substâncias pelas células imobilizadas, que diferem das sintetizadas pelo talo in natura, não significa insucesso da metodologia. A produção de compostos intermediários já é uma resposta positiva à técnica empregada, sobretudo se for considerada a hipótese da bioconservação da espécie. Técnicas de culturas de liquens 


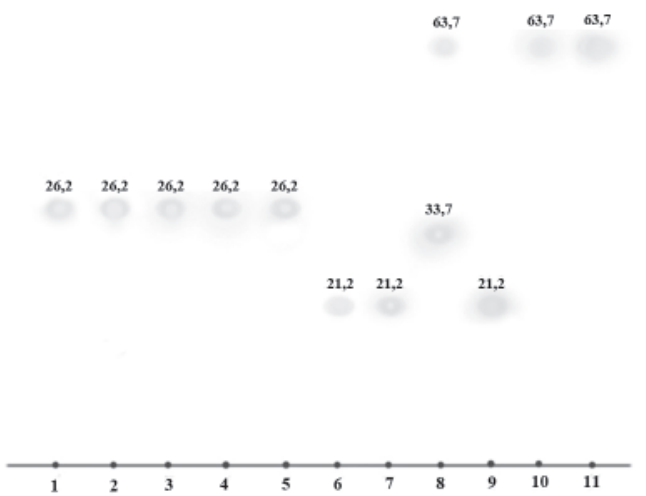

Figura 3. Cromatograma em camada delgada dos eluatos celulares: (1) 0,01 mM; (2) 0,1 mM; (3) 1,0 mM; (4); 10,0 mM; (5) 20,0 mM; extratos: (6) etéreo; (7) clorofórmico; (8) acetônico; substâncias isoladas: (9) ácido lecanórico; (10) atranorina; padrão: (11) atranorina.

in vitro, por exemplo, além de dispendiosas, levam meses para o desenvolvimento de talos rudimentares, e a produção é dificultada pelos mesmos problemas (Blanco et al., 2002).

Não foi observada atividade antimicrobiana nos eluatos celulares de $P$. Andinum. Possivelmente as substâncias produzidas podem ser intermediárias de rotas metabólicas, semelhantes estruturalmente mas sem o mesmo espectro de atividades biológicas do ácido lecanórico e da atranorina. Gomes et al. (2006) demonstraram fenômeno semelhante modificando o ácido lecanórico, através de alcoólise e identificando um aumento da atividade citotóxica dos produtos obtidos, relacionada a um aumento na sua lipofilicidade. Umezawa et al. (1984), observaram atividade inibitória sobre histidina decarboxilase, enzima relacionada a tumores de pele, em análogos do ácido lecanórico, mais especificamente 3,5'-dicloro-2,4'-dihidroxibenzanilideo.

Quanto aos extratos orgânicos, verificou-se sua atividade frente à Micrococcus lutteus, Bacillus subtilis e Staphylococcus aureus. Observou-se que o extrato com maior espectro de atividade foi o etéreo, apresentando halos de inibição significativos frente B.subtilis, S. aureus e M. lutteus. Já o extrato clorofórmico apresentou o maior halo de inibição frente o B. subtilis, enquanto o extrato acetônico apresentou um pequeno halo inibitório frente a $M$. lutteus. Todos os extratos foram menos ativos que os padrões utilizados nos experimentos (Tab. 1). Estes resultados estão de acordo com aqueles obtidos por outros pesquisadores, os quais referem uma maior sensibilidade das bactérias Gram-positivas às substâncias liquênicas (Ribeiro et al., 2002).

O ensaio biocromatográfico foi realizado com o intuito de se identificar os compostos ativos presentes nos extratos de $P$. andinum, sendo selecionado o extrato mais ativo (clorofórmico) frente ao microrganismo mais sensível (Bacillus subtilis) nos ensaios em cultura. Neste teste (Fig. 9) foram observados halos de inibição em torno das bandas correspondentes ao ácido lecanórico

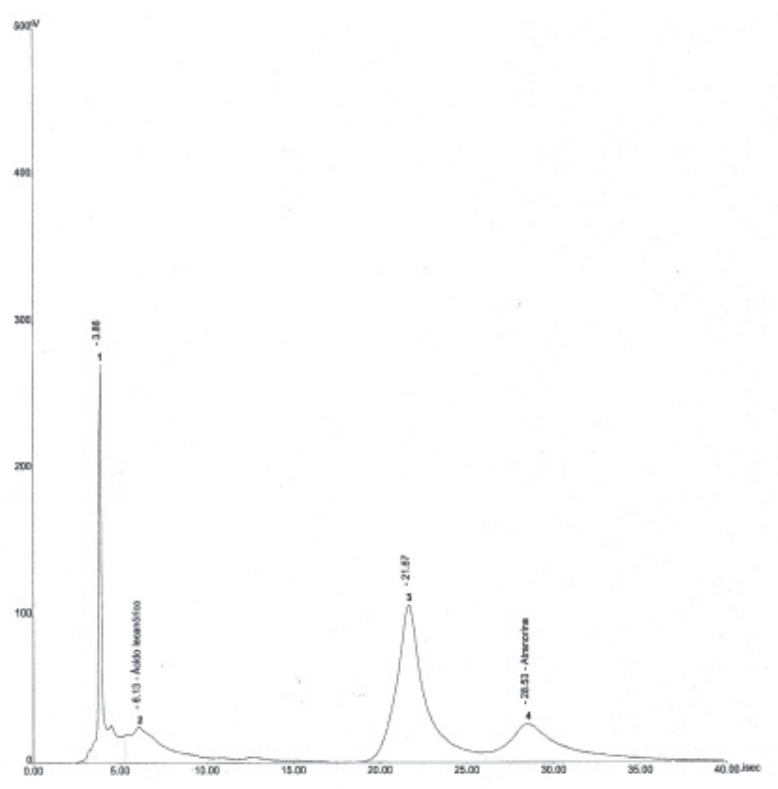

Figura 4. Cromatografia líquida de alta eficiência do extrato etéreo obtido a partir do talo in natura de Parmotrema andinum na concentração de $1,0 \mathrm{mg} \mathrm{mL}^{-1}$.

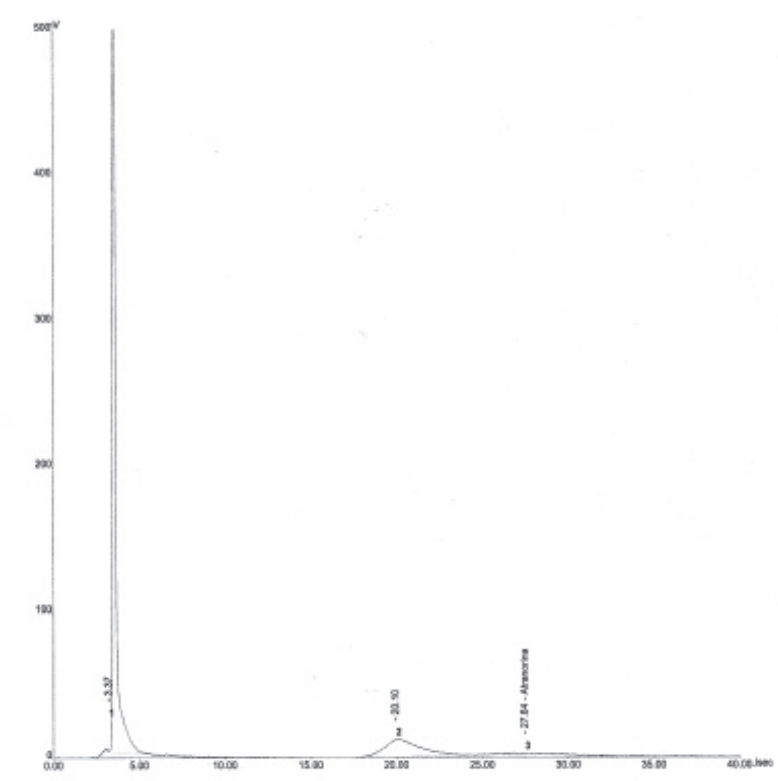

Figura 5. Cromatografia líquida de alta eficiência do extrato clorofórmico obtido a partir talo in natura de Parmotrema andinum na concentração de $1,0 \mathrm{mg} \mathrm{mL}^{-1}$.

(15 mm) e da substância não identificada presente no extrato clorofórmico $(40 \mathrm{~mm})$. Os resultados demonstram ainda, que o ácido lecanórico pode ser co-responsável pela atividade antibacteriana, agindo sinergicamente com outras substâncias.

Maia et al. (2002) referem atividade antinflamatória à atranorina. Da mesma forma, tal composto é mencionado por Falcão et al. (2002) como principio ativo dos extratos orgânicos da espécie Heterodermia leucomela, descrevendo a atividade inibitória frente a bactérias Gram-positivas. 
Nadejda de Azevedo Nóbrega, Sheyla Mara Ribeiro, Eugênia Cristina Pereira, Marcelo Marcelli, Mônica Cristina Barroso Martins, Emerson Peter da Silva Falcão, Norma Buarque de Gusmão e Nicácio Henrique da Silva

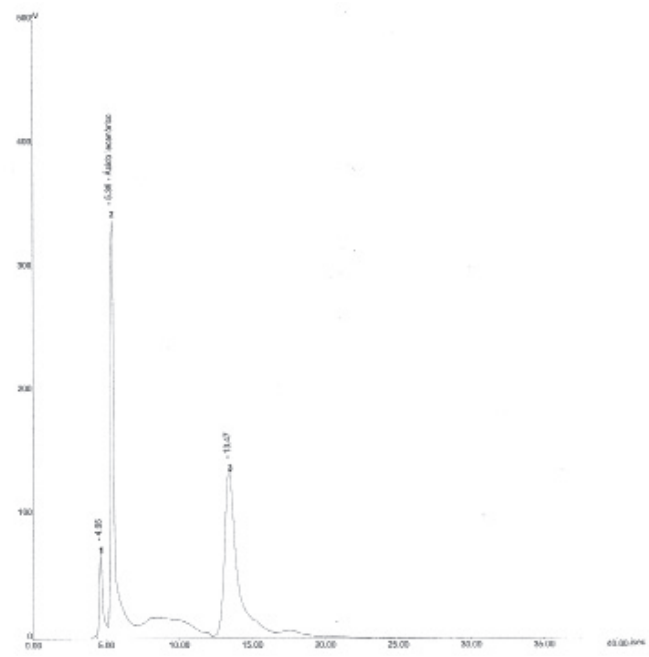

Figura 6. Cromatografia líquida de alta eficiência do extrato acetônico obtido a partir talo in natura de Parmotrema andinum na concentração de $1,0 \mathrm{mg} \mathrm{mL}^{-1}$.

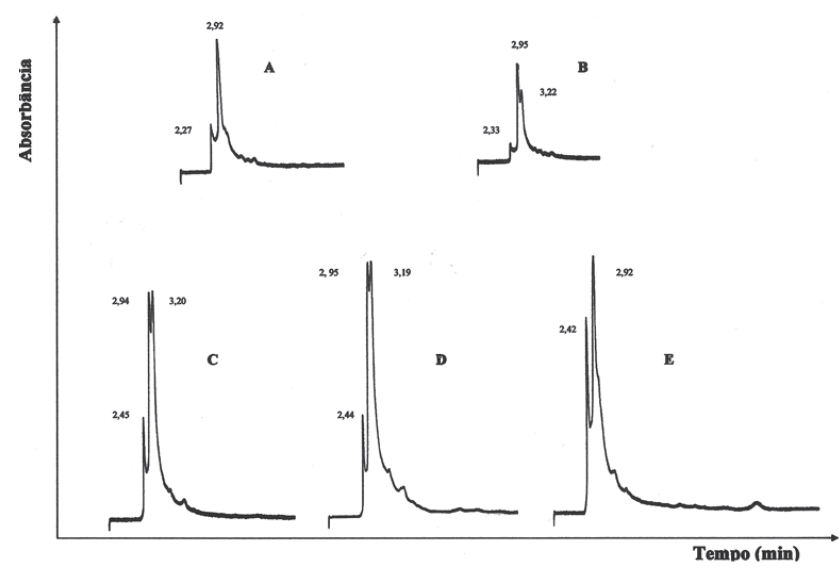

Figura 7. Cromatografia líquida de alta eficiência do eluatos celulares na concentração de $0,1 \mathrm{mg} \mathrm{mL}^{-1}$ obtidos por imobilização em caulinita, das células extraídas do talo de Parmotrema andinum. Concentração do acetato de sódio: (A) 0,01 mM; (B) 0,1 mM; (C) 1,0 mM; (D) 10,0 mM; (E) 20,0 mM.

Tabela 1. Atividade antimicrobiana dos extratos orgânicos, etéreo, clorofórmico e acetônico obtidos a partir do talo in natura de Parmotrema andinum expressos através de halo de inibição mensurados em mm.

\begin{tabular}{|c|c|c|c|c|}
\hline \multirow{2}{*}{ Extratos/Substâncias } & \multirow{2}{*}{$\begin{array}{l}\text { Concentração } \\
\left(\mathrm{mg} \cdot \mathrm{mL}^{-1}\right)\end{array}$} & \multicolumn{3}{|c|}{ Microrganismos } \\
\hline & & Bacillus subtilis & Staphylococcus aureus & Micrococcus lutteus \\
\hline \multirow{2}{*}{ Extrato etéreo } & 1 & 8 & 11 & 13 \\
\hline & 2 & 17 & 11 & 19 \\
\hline \multirow{2}{*}{ Extrato clorofórmico } & 1 & 18 & 9 & - \\
\hline & 2 & 20 & 13 & - \\
\hline \multirow{2}{*}{ Extrato acetônico } & 1 & - & - & - \\
\hline & 2 & - & - & 8 \\
\hline \multirow{2}{*}{ Atranorina } & 1 & - & - & - \\
\hline & 2 & - & 12 & 9 \\
\hline \multirow{2}{*}{ Ácido lecanórico } & 1 & 19 & 15 & 10 \\
\hline & 2 & 21 & 18 & 15 \\
\hline \multirow{2}{*}{ Ácido úsnico } & 1 & 20 & 13 & 18 \\
\hline & 2 & 25 & 13 & 22 \\
\hline Levofloxacino & $0,5 \mu \mathrm{g} \mathrm{mL}^{-1}$ & 38 & 27 & 33 \\
\hline
\end{tabular}
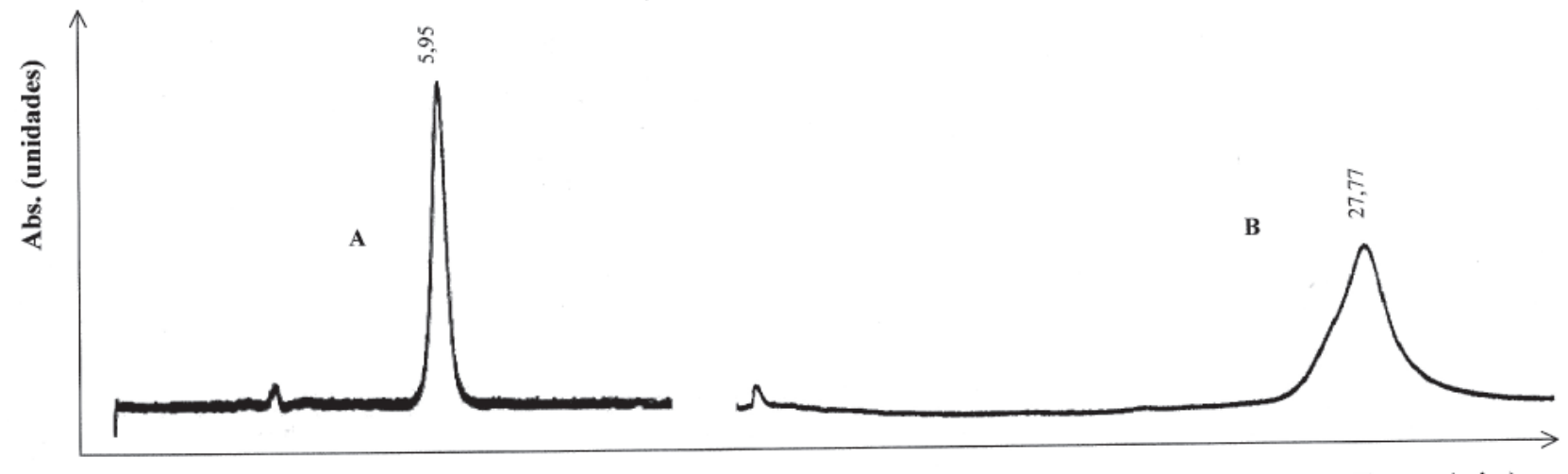

Figura 8. Cromatografia líquida de alta eficiência dos padrões ácido lecanórico (A) e atranorina (B) na concentração de $0,1 \mathrm{mg} \mathrm{mL}^{-1}$. 


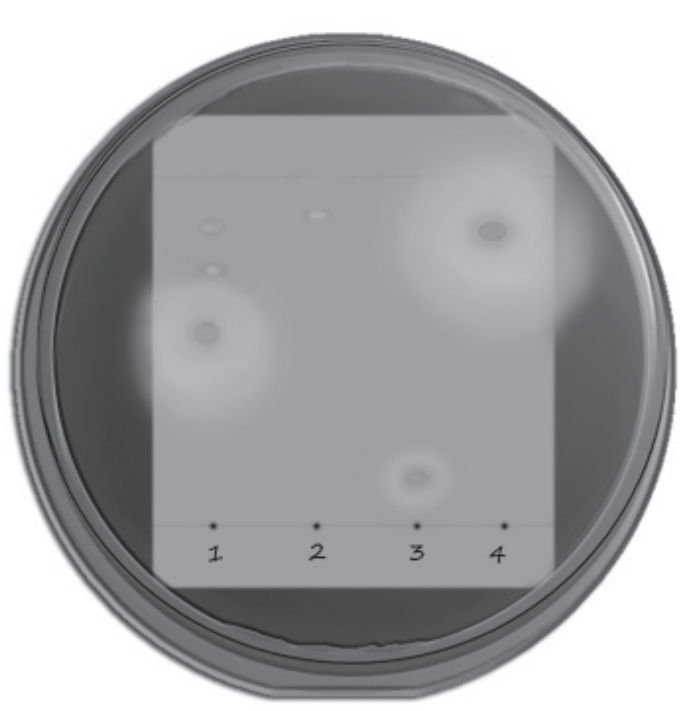

Figura 9. Biocromatograma utilizando o extrato clorofórmico a $3,0 \mathrm{mg} \mathrm{mL} \mathrm{m}^{-1}$ obtido a partir do talo in natura de Parmotrema andinum contra o Bacillus subtilis na concentração de $10^{7} \mathrm{UFC} \mathrm{mL}^{-1}$. (1) extrato clorofórmico. Padrões: (2) ácido úsnico; (3) ácido lecanórico; (4) atranorina.

A análise cromatográfica revelou a presença de dois compostos não identificados, o que torna necessária a continuidade das pesquisas. Em adição, existem indícios experimentais de atividade antimicrobiana em uma das mencionadas substâncias.

O sistema de imobilização adotado para o experimento foi eficiente na manutenção da vitalidade liquênica, mas, não levou à produção dos compostos principais descritos para a espécie. Uma explicação plausível seria a de que a união física dos simbiontes é fundamental à indução para produção dos metabólitos em questão. Entretanto, talvez a adição de outros microelementos ao sistema de cultivo possa ser necessária, o que suscinta maiores estudos.

\section{Agradecimentos}

Laboratório de Microbiologia no Departamento de Antibióticos da Universidade Federal de Pernambuco - UFPE, Brasil pela disponibilização de infra-estrutura e dos microrganismos.

\section{Referências Bibliográficas}

Asahina Y. \& Shibata, S. 1954. Chemistry of lichen substances. Japan Society for the Promotion of Science.

Blanco, Y.; Blanch, M.; Fontaniella, B.; Legaz, M.E.; Millanis, A.M.; Pereira, E.C. \& Vicente, C. 2002. Bioproduction of lichen phenolics by immobilized lichen cells with emphasis on the role of epiphytic bacteria. Journal of Hattori Botany Laboratory 92: 245-260.

Bauer, A.W.; Kirby, W.M.M.; Sherris, J.C. \& Truck, M. 1966. Susceptibility testing by a standardized single disk method. American Journal of Clinical Pathology 45: 493-496.
Cullberson, C.F. 1972. Improved conditions and new data for the identification of lichen products by a standardized thinlayer-chromatographic method. Journal of Cromatography 72: 113-125.

Falcão, E.P.S.; Silva, H.H.; Pereira, E.C.; Gusmão, N.B. \& Ribeiro, S.M. 2002. Avaliação da atividade antimicrobiana de compostos fenólicos de Heterodermia leucomela (L.) Poelt. Acta Farmaceutica Bonaerense 21(1): 43-49.

Gomes, A.T.; Honda, N.K.; Roese, F.M.; Muzzi, R.M. \& Sauer, L. 2006. Cytotoxic activity of orsellinates. Zeitschrift für Naturforschung [C] 61(9-10): 653-657.

Jayaprakasha, G.K. \& Rao, L.J. 2000. Phaenolic Constituents of the lichen Parmotrema stuppeum (Nyl.) Hale and their antioxidant activity. Zeitschrift für Naturforschung [C] 55(11-12): 1018-1022.

Legaz, M.E. \& Vicente, C. 1983. Endogenous inactivators of arginase, 1arginine decarboxylase, and agmatine amidinohydrolase in Evernia prunastri thallus. Plant Fisiology 71: 300-302.

Maia, M.B.S.; N.H. Silva, E.F. Silva; M.T. Catanho, A.R.P. Shuler. \& E.C. Pereira. 2002. Antinociceptive activity of crude extracts and atranorin obtained from the lichen Cladina dendroides (des Abb.) Ahti. Acta Farmaceutica Bonaerense 21(1): 43-49.

Millot, M.; Tomasi, S.; Articus, K.; Rouaud, I.; Bernard, A. \& Boustie, J. 2007. Metabolites from the Lichen Ochrolechia parella growing under two different heliotropic conditions. Journal of Naural Products 70(2): 316-8.

Nash III, T.H. 2008. Lichen Biology. 2 ed. Cambridge, Cambridge University Press.

Pereira, E.C.; Pereyra, M.T.; Matos, S.C.; Silva, N.H.; Andrade, L. \& Vicente, C. 1995. Bioproduction of usnic acid from acetate by kaolinite immobilized cells of Cladonia substellata vainio. Acta Societatis Botanicorum Poloniae 64(2): 171-174.

Pereira, E.C.; Silva, N.H.; Campos Takaki, G.M.; Xavier-Lauro, L.; Legaz, M.E. \& Vicente, C. 1997. Antimicrobial activity and biologically-acive compounds from lichen Cladonia crispatula, Boletim Ecotropica Ecossistemas Tropicais 31: 9-19.

Pereira, E.C.; Silva, N.H.; Andrade, L.C.; Vicente, C. \& Legaz., M.E. 1999. Production of lichen metabolites through cell immobilization by Cladonia clathrata Ahti \& Xavier-Filho. Phyton 39: 79-89.

Pereira, E.C.; Silva, E.F.; Silva, I.M.L.; Vital, M.I.S.; Silva, N.H.; Vicente, C. \& Andrade, L.H.C. 1999. Produção de metabólitos de Cladonia corallifera (Kunze) Nyl. - por imobilização celular. Revista da Universidade do Amazonas 2: 25-41.

Pereira, E.C.; Andrade, L.C.; Silva, N.H. \& Vicente, C. 2002. Production of metabolites by immobilized cells of Cladia aggregata (Sw.) Nyl. At different status of fertility. Pp. 157-69. In: Calvelo S. \& Feuere, T. (Eds.) Lichenology in Latin America II. Hamburg, Mitt. Inst. Allg. Bot. Hamburg.

Ribeiro, S.M.; Pereira, E.C.; Silva, N.H.; Falcão, E.P.S.; Gusmão, N.B.; Honda, N.K. \& Quilhot, W. 2002. Detection of antibacterial activity of lichen substances through microdilution tests. Pp. 187-194. In: Calvelo, S. \& Feuerer, T. (Org.). Lichenology in Latin America II. Hamburg, Mitt. Inst. Allg. Bot. Hamburg.

Shibata, S.; Tosa, T.; Sato, T.; Nishida, Y. \& Chibata, I. 1987. Imobilization of cells in carrageenan. Methods in Enzymology 135: 189-198.

Svitel, J.; Curilla, O.; Tkac, J. 1998. Microbial cell-based biosensor for sensing glucose, sucorose or lactose. Biotechnology apllied biochemistry 27: 153-158.

Umezawa, K.; Matsushima, T.; Sawa, T.; Takeuchi, T.; Hirono, I. 1984. 3'5'-Dichloro-2,4'-dihydroxybenzanilide, an inhibitor of histidine decarboxylase, inhibited skin tumor promotion induced by 12-O-tetradecanoylphorbol-13-acetate in mice. Experientia 40(1): 100-1.

Yamamoto, Y.; Tosa, T.; Tamashita, K.; Shibata, S. 1976. Continuous production of L-malic acid by immobilized Brevibacterium ammoniagenes cells. European Applied Microbiology 3: 169-183 